\title{
BMJ
}

\section{Risk of recurrence after a first seizure and implications for driving: further analysis of the Multicentre study of early Epilepsy and Single Seizures}

Department of Biostatistics,

University of Liverpool

${ }^{2}$ Clinical and Molecular

Pharmacology, University of Liverpool

Correspondence to: A G Marson

A.G.Marson@liverpool.ac.uk

Cite this as: BMJ 2010;341:c6477 doi:10.1136/bmi.c6477

\section{LJ Bonnett, statistical research assistant, ${ }^{1} \mathrm{C}$ Tudur-Smith, senior lecturer in medical statistics, ${ }^{1} \mathrm{P}$ R Williamson, director and professor of medical statistics, ${ }^{1}$ A G Marson, professor of neurology ${ }^{2}$}

\section{ABSTRACT}

Objective To determine for how long after a first unprovoked seizure a driver must be seizure-free before the risk of recurrence in the next 12 months falls below $20 \%$, enabling them to regain their driving licence. Design Randomised controlled trial: Multicentre study of early Epilepsy and Single Seizures (MESS).

Setting UK hospital outpatient clinics from 1 January 1993 to 31 December 2000.

Participants People entered MESS if they had had one or more unprovoked seizures and both the participant and the clinician were uncertain about the need to start antiepileptic drug treatment. The subset of people used for this analysis comprised participants aged at least 16 years with a single unprovoked seizure.

Main outcome measure Risk of seizure recurrence in the 12 months after a seizure-free period of $6,12,18$, or 24 months from the date of the first (index) seizure. Regression modelling was used to investigate how antiepileptic treatment and several clinical factors influence the risk of seizure recurrence.

Results At six months after the index seizure the risk of recurrence in the next 12 months for those who start antiepileptic drugs was significantly below $20 \%$ (unadjusted risk 14\%, 95\% confidence interval 10\% to $18 \%)$. For patients who did not start treatment the risk estimate was less than $20 \%$ but the upper limit of the confidence interval was greater than $20 \%$ (18\%, $13 \%$ to $23 \%)$. Multivariable analyses identified subgroups with a significantly greater than $20 \%$ risk of seizure recurrence in the 12 months after a six month seizure-free period, such as those with a remote symptomatic seizure with abnormal electroencephalogram results.

Conclusion After a single unprovoked seizure this reanalysis of MESS provides estimates of seizure recurrence risks that will inform policy and guidance about regaining an ordinary driving licence. Further guidance is needed as to how such data should be utilised; in particular, whether a population approach should be taken with a focus on the unadjusted results or whether attempts should be made to individualise risk. Guidance is also required as to whether the focus should be on risk estimates only or on the confidence interval as well. If the focus is on the estimate only our unadjusted estimates suggest that treated and untreated patients are eligible to drive after being seizure-free for six months. If the focus is also on confidence intervals, direction is needed as to whether a conservative or liberal approach should be taken.

Trial registration Current Controlled Trials ISRCTN98767960.

\section{INTRODUCTION}

Driving regulations in the European Union currently differ among member states. ${ }^{1}$ In 1995 and 1996 the International League Against Epilepsy and the International Bureau for Epilepsy organised workshops to discuss driving regulations around epilepsy and seizures, but the recommendations were never reflected in an official European guideline or in European law. Following further calls for harmonisation across the European Union, ${ }^{2-4}$ member states have been engaged in a process of identifying minimum standards for driving, and these are now in the process of being implemented in the United Kingdom and other European Union states. Where possible the United Kingdom based Driving and Vehicle Licensing Agency adopt a risk based approach to determine who can return to driving after an incapacitating event such as an epileptic seizure. ${ }^{5}$ Epilepsy comes under the 1988 Road Traffic Act, but single seizures, which by definition do not constitute epilepsy, come under the domestic regulations (1999 Motor Vehicles (Driving Licences) Regulations). People who have had a single unprovoked seizure are usually allowed to regain their ordinary (group 1) driving licence six months after the event provided their risk of a seizure recurrence in the next year is below 20\%. Drivers can regain their heavy goods vehicle (group 2) licence after five years provided their risk of a recurrence is below $2 \%$ and they have not been taking antiepileptic drugs for five years. Although these minimum risk levels of $20 \%$ and $2 \%$ are somewhat arbitrary, they are supported by other member states ${ }^{4}$ and have been adopted in the criteria determining minimum driving standards that are being harmonised across the European Union. We are not 


\begin{tabular}{|c|c|c|c|}
\hline Characteristic & $\begin{array}{l}\text { Immediate treatment } \\
\qquad(\mathrm{n}=317)\end{array}$ & $\begin{array}{l}\text { Delayed treatment } \\
\qquad(n=320)\end{array}$ & $\begin{array}{c}\text { Total } \\
(n=637)\end{array}$ \\
\hline $\begin{array}{l}\text { Median (interquartile range) age } \\
\text { at randomisation (years) }\end{array}$ & $32.0(21.5-49.5)$ & $33.8(22.4-50.6)$ & $32.9(21.9-50.3)$ \\
\hline Male & $199(63)$ & $213(67)$ & $412(645)$ \\
\hline Female & $118(37)$ & $107(33)$ & $225(35)$ \\
\hline \multicolumn{4}{|l|}{ Cause of seizure: } \\
\hline Remote symptomatic & $55(17)$ & $49(15)$ & $104(16)$ \\
\hline Not remote symptomatic & $262(83)$ & $271(85)$ & $533(84)$ \\
\hline \multicolumn{4}{|l|}{ Neurological deficit: } \\
\hline Absent & $288(91)$ & $299(94)$ & $587(92)$ \\
\hline Present & $27(8)$ & $19(5)$ & $46(7)$ \\
\hline Missing & $2(1)$ & $2(1)$ & $4(1)$ \\
\hline \multicolumn{4}{|l|}{ Previous acute symptomatic seizures: } \\
\hline Febrile & $15(5)$ & $14(4)$ & $29(5)$ \\
\hline Other & $1(0)$ & $7(2)$ & $8(1)$ \\
\hline None & $301(95)$ & $299(94)$ & $600(94)$ \\
\hline \multicolumn{4}{|l|}{ Epilepsy in first degree relative: } \\
\hline Yes & $33(10)$ & $34(11)$ & $67(10)$ \\
\hline No & $284(90)$ & $286(89)$ & $570(90)$ \\
\hline \multicolumn{4}{|l|}{ Seizures: } \\
\hline Partial & $102(32)$ & $100(31)$ & $202(32)$ \\
\hline Generalised or not definitely partial & $205(65)$ & $217(68)$ & $422(66)$ \\
\hline Other & $10(3)$ & $3(1)$ & $13(2)$ \\
\hline \multicolumn{4}{|l|}{ Seizures only while asleep: } \\
\hline Yes & $65(20)$ & $50(16)$ & 115 (18) \\
\hline No & $252(80)$ & $269(84)$ & $521(82)$ \\
\hline Missing & - & $1(0)$ & $1(0)$ \\
\hline \multicolumn{4}{|l|}{ EEG results: } \\
\hline Normal & $147(46)$ & $136(43)$ & $283(44)$ \\
\hline Abnormal & $149(47)$ & $160(50)$ & 309 (49) \\
\hline Not done or missing & $21(7)$ & $24(7)$ & $45(7)$ \\
\hline \multicolumn{4}{|l|}{ CT or MRI scan results: } \\
\hline Normal & $219(69)$ & $231(72)$ & $450(71)$ \\
\hline Abnormal & $38(12)$ & 34 (11) & $72(11)$ \\
\hline Not done or missing & 60 (19) & $55(17)$ & $115(18)$ \\
\hline
\end{tabular}

aware of any countries outside the European Union that have such a risk based approach. In the United States each individual state has its own legislation for driving with epilepsy and seizures. When surveyed in $2001^{6}$ most states $(n=28)$ required people with epilepsy to have a time off driving (median six months), whereas in 19 states the time was decided by the treating doctor or a medical advisory board.

When implementing the new European Union legislation, member states may adopt the minimum standard and should not allow a more lenient standard. Member states can, however, adopt a stricter standard provided it can be justified, although it is likely that any state that sets a more stringent standard would face a challenge in court. In October 2009, after a discussion at a meeting of the Driving and Vehicle Licensing Agency's neurology panel, at which the findings in this paper were also discussed, the agency altered its guidance. ${ }^{5}$ It stated that after a first unprovoked seizure drivers could regain their ordinary licence once they had been seizure-free for six months provided that their risk of a recurrence over the next year was below this 20\% cut-off. Few published studies have estimated the risk of seizure recurrence and investigated factors that modify risk. Publications that do exist ${ }^{78}$ have focused on recurrence immediately after a first seizure and none have presented risks of recurrence in the next 12 months at time points such as six or 12 months after an index seizure. Reliable published data are therefore needed to inform decisions made by clinicians, Driving and Vehicle Licensing Agency guidance or European Union legislation, and legislation outside the European Union.

The Multicentre study of early Epilepsy and Single Seizures (MESS) ${ }^{9}$ was a randomised controlled trial that compared the policies of immediate or deferred treatment in people presenting with a first unprovoked seizure or with early epilepsy. The trial remains the largest reported study of patients with single seizures and early epilepsy, and although the primary purpose of the study was to compare treatment policies, it also provided an important opportunity to examine the risks of seizure recurrence and factors that modify those risks. Outcomes assessed included time to seizure recurrence, time to two year remission, and quality of life. In this paper we analysed data from participants with only a single unprovoked seizure, referred to as the index seizure, at entry into the MESS study to estimate seizure recurrence risk in the 12 months after the index seizure. We used modelling to investigate how antiepileptic drug treatment and several clinical factors influence the risk of seizure recurrence.

\section{METHODS}

The methods for the MESS study have been published elsewhere. ${ }^{9}$ Briefly, patients were eligible for inclusion if they were at least one month old; had had at least one clinically definite, spontaneous, unprovoked epileptic seizure; and if both the clinician and the patient (or carer) were uncertain about whether or not to start antiepileptic drugs. Exclusion criteria included previous treatment with antiepileptic drugs or the presence of a progressive neurological disease. People were recruited to the trial between 1 January 1993 and 31 December 2000 and were followed up, if possible, from 31 December 2001 to 30 June 2002. After the recruiting doctor had obtained informed consent and enrolled the participant, participants were allocated randomly to treatment policy by phone or fax by way of the minimisation method, which was balanced across centre or region and number of seizures at randomisation. For participants assigned to immediate treatment, the clinician selected the optimum antiepileptic drug, based on their usual practice, and started treatment as early as possible. Participants assigned to deferred treatment received no drugs until the clinician and patient agreed that it was necessary, mainly after a seizure recurrence. 
Table 2 | Risk of seizure recurrence over 12 months at time points after index seizure: risk (\%, $95 \%$ confidence interval)

\begin{tabular}{|c|c|c|c|c|}
\hline \multirow[b]{2}{*}{$\begin{array}{l}\text { Time after index seizure } \\
\text { (months) }\end{array}$} & \multicolumn{2}{|c|}{ Immediate treatment } & \multicolumn{2}{|c|}{ Delayed treatment } \\
\hline & No at risk & $\begin{array}{c}\text { Risk of seizure } \\
\text { in next } 12 \text { months }\end{array}$ & No at risk & $\begin{array}{c}\text { Risk of seizure } \\
\text { in next } 12 \text { months }\end{array}$ \\
\hline 6 & 260 & 14 (10 to 18$)$ & 254 & 18 (13 to 23$)$ \\
\hline 12 & 230 & $7(4$ to 11$)$ & 219 & 10 (6 to 15$)$ \\
\hline 18 & 211 & $8(5$ to 12$)$ & 197 & 12 (8 to 17$)$ \\
\hline 24 & 199 & 7 (3 to 10$)$ & 182 & $10(5$ to 14$)$ \\
\hline
\end{tabular}

We obtained baseline clinical information and demographic data for all randomised participants and those eligible people who did not provide consent for randomisation. Electroencephalography was requested for all randomised participants, and brain imaging (computed tomography or magnetic resonance imaging) was undertaken if clinically indicated. Follow-up occurred at three, six, and 12 months and successive yearly intervals from randomisation, with additional visits as clinically indicated. At each visit the occurrence and type of seizure was recorded, together with antiepileptic drugs and any adverse events.

In the original MESS study outcomes were time from randomisation to first seizure, to first tonic-clonic seizure, and to second and fifth seizure; time to two year remission; the proportion of patients seizure-free for two years between one and three years after randomisation and three and five years after randomisation; adverse events; and quality of life. To make the analysis reported here relevant to those of driving age, we included participants with a single seizure only and aged 16 years or over. We chose 16 as the lower cutoff as by age 17, after 12 months of follow-up, these participants would be eligible for a provisional licence.

Patients were classified as remote symptomatic if on entry to MESS the clinician considered that their seizure was caused by a remote disease or event such as a head injury; meningitis or encephalitis, or both; intracranial surgery; or other disease. Neurological deficit included hemiparesis and learning difficulty, and an abnormal electroencephalogram was defined as epileptiform activity with focal or generalised spikes or spike and slow wave activity.

\section{Statistical analysis}

We restricted our analyses to those aged 16 years or older with a single seizure on entry into MESS. Although MESS was a randomised trial, in this analysis we measured time to event from the date of the first seizure, occurring before study entry, referred to as the index seizure, and not the date of randomisation. The outcome of interest was the probability of being seizure-free for the next 12 months having been seizure-free from the index seizure to the time point in question. For example, the probability of someone who was seizure-free for six months after his or her index seizure, remaining seizure-free for seven to 18 months was calculated by dividing the probability of being seizure-free for 18 months by the probability of being seizure-free for six months. We similarly calculated the risks of recurrence in the next 12 months for other time points, and used a revised version of Greenwood's formula to calculate the confidence intervals for these estimates. ${ }^{10-12}$

We determined those variables associated with a higher risk of seizure recurrence both univariately and after adjusting for multiple variables using logrank tests and Cox proportional hazards modelling methods. We produced a best fitting, parsimonious, multivariable model with variable reduction by Akaike's information criterion. ${ }^{13}$ For this model we excluded missing values except in the case of results for electroencephalography and computed tomography or magnetic resonance imaging, where we created a third category for missing or not done. From the multivariable model we calculated the risk of recurrence in the next 12 months for combinations of risk factors. ${ }^{14}$

\section{RESULTS}

The figure shows the flow of patients through the study. Consent was not obtained for 404 of 1847 eligible patients. The remaining 1443 patients were randomised; 722 to immediate antiepileptic drug treatment, of whom $317 \mathrm{had}$ a recorded date of index seizure and were analysed, and 721 to deferred antiepileptic drug treatment, of whom 320 were analysed. Table 1 summarises the characteristics of the patients.

In the immediate treatment group the unadjusted risk of recurrence in the next 12 months at six months after the index seizure was $14 \%(95 \%$ confidence interval $10 \%$ to $18 \%$ ), significantly below $20 \%$ (table 2 ). For the delayed treatment group the estimate was $18 \%$ but the confidence interval (13\% to 23\%) did not exclude a $20 \%$ risk of recurrence. At 12 months, however, the risk was reduced to $10 \%(6 \%$ to $15 \%)$, significantly below $20 \%$.

Treatment policy was included as a covariate for the univariate and the multivariable modelling (table 3). In the univariate model factors significantly associated with a higher risk of seizure recurrence were a remote

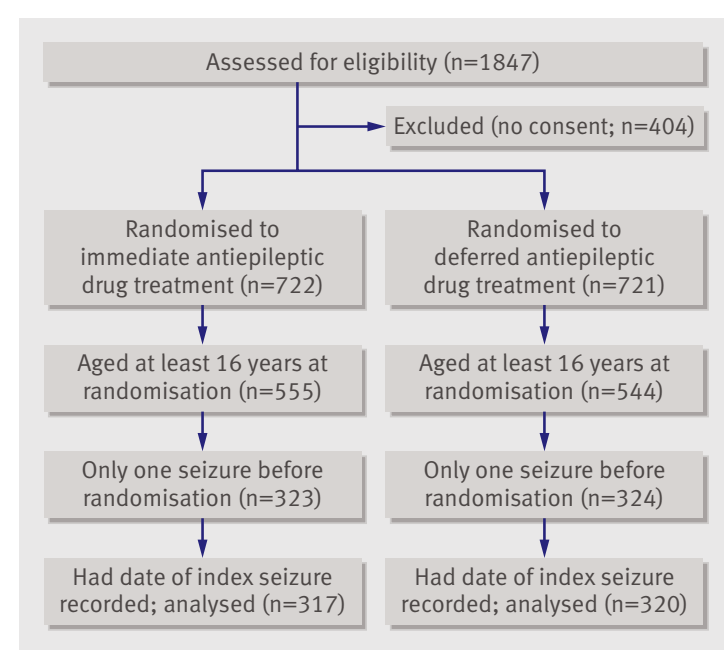

Flow of patients through study 
Table 3 |Effect estimates from univariate and multivariable models

\begin{tabular}{|c|c|c|c|}
\hline Variables & $\begin{array}{l}\text { Univariate } P \\
\text { value }\end{array}$ & $\begin{array}{l}\text { Univariate hazard ratio } \\
\qquad(95 \% \mathrm{Cl})\end{array}$ & $\begin{array}{l}\text { Multivariable hazard } \\
\text { ratio }(95 \% \mathrm{Cl})\end{array}$ \\
\hline \multicolumn{4}{|l|}{ Age at randomisation (years): } \\
\hline $16 \vee 25$ & \multirow{4}{*}{0.71} & 1.00 & NA \\
\hline $25 \vee 35$ & & $0.86(0.59$ to 1.23$)$ & \\
\hline $35 \vee 50$ & & $1.00(0.72$ to 1.39$)$ & \\
\hline$\geq 50$ & & $1.08(0.79$ to 1.48$)$ & \\
\hline \multicolumn{4}{|l|}{ Sex: } \\
\hline Men & \multirow{2}{*}{0.42} & 1.00 & NA \\
\hline Women & & $0.90(0.69$ to 1.16$)$ & \\
\hline \multicolumn{4}{|l|}{ Cause of seizure: } \\
\hline Not remote symptomatic & \multirow{2}{*}{$0.02^{*}$} & 1.00 & 1.00 \\
\hline Remote symptomatic & & $1.45(1.06 \text { to } 1.98)^{\star}$ & $1.33(0.95$ to 1.87$)$ \\
\hline \multicolumn{4}{|l|}{ Neurological deficit: } \\
\hline Absent & \multirow{2}{*}{$0.01^{*}$} & 1.00 & NA \\
\hline Present & & $1.80(1.17 \text { to } 2.76)^{\star}$ & \\
\hline \multicolumn{4}{|l|}{ Acute symptomatic seizures: } \\
\hline None & \multirow{3}{*}{0.96} & 1.00 & NA \\
\hline Febrile seizures & & $0.98(0.55$ to 1.75$)$ & \\
\hline Other & & $1.17(0.37$ to 3.65$)$ & \\
\hline \multicolumn{4}{|l|}{ Epilepsy in first degree relative: } \\
\hline No & \multirow{2}{*}{0.07} & 1.00 & 1.00 \\
\hline Yes & & $1.37(0.97$ to 1.94$)$ & $1.33(0.94$ to 1.90$)$ \\
\hline \multicolumn{4}{|l|}{ Seizure type: } \\
\hline Generalised or not definitely focal & \multirow{3}{*}{0.23} & 1.00 & NA \\
\hline Partial & & $0.79(0.61$ to 1.04$)$ & \\
\hline Other & & $0.83(0.34$ to 2.01$)$ & \\
\hline \multicolumn{4}{|l|}{ Seizures only while asleep: } \\
\hline No & \multirow{2}{*}{$0.01^{*}$} & 1.00 & 1.00 \\
\hline Yes & & $1.49(1.11 \text { to } 2.00)^{\star}$ & $1.47(1.09 \text { to } 1.97)^{\star}$ \\
\hline \multicolumn{4}{|l|}{ EEG results: } \\
\hline Normal & \multirow{3}{*}{$0.00^{*}$} & 1.00 & 1.00 \\
\hline Abnormal & & $1.62(1.25 \text { to } 2.09)^{\star}$ & $1.55(1.20 \text { to } 2.01)^{*}$ \\
\hline Not done or missing & & $1.48(0.86 \text { to } 2.55)^{\star}$ & $1.29(0.74 \text { to } 2.27)^{\star}$ \\
\hline \multicolumn{4}{|l|}{ CT or MRI scan results: } \\
\hline Normal & \multirow{3}{*}{0.08} & 1.00 & 1.00 \\
\hline Abnormal & & $1.32(0.91 \text { to } 1.91)^{\star}$ & $1.07(0.72$ to 1.61$)$ \\
\hline Not done or missing & & $1.37(1.00 \text { to } 1.86)^{\star}$ & 1.29 (0.94 to 1.78$)$ \\
\hline \multicolumn{4}{|l|}{ Treatment policy: } \\
\hline Delayed & \multirow{2}{*}{0.13} & 1.00 & 1.00 \\
\hline Immediate & & 0.83 (0.65 to 1.06$)$ & 0.82 (0.64 to 1.05$)$ \\
\hline
\end{tabular}

$\mathrm{NA}=$ not applicable; Electroencephalogram=EEG; $C \mathrm{CT}=$ computed tomography; $\mathrm{MRI}=$ magnetic resonance imaging. *Significant result. interval (13\% to $49 \%)$ did not exclude the possibility of the risk being below $20 \%$.

In the multivariable analysis (table 3 ) the parsimonious model included variables for cause of the seizure, epilepsy in a first degree relative, seizure while asleep, electroencephalogram results, computed tomography or magnetic resonance imaging scan results, and treatment policy. No evidence suggested that the proportional hazards assumption, underlying the Cox model, was invalid. From the model, remote symptomatic seizure, seizure while asleep, and an abnormal electroencephalogram result were associated with a higher risk of seizure recurrence, but again treatment policy was not a significant factor.

The risk of recurrence at 12 months for patients with particular characteristics was estimated from the parsimonious multiple regression model. As a large number of combinations was possible table 5 shows selected results for remote and non-remote symptomatic seizure, electroencephalogram result, and computed tomography or magnetic resonance imaging scan results assuming that the index seizure was not during sleep and that participants did not have a first degree relative with epilepsy. The table on bmj.com shows the estimates for all possible combinations of factors.

Although the unadjusted results suggested that patients who start treatment after a single seizure and are seizure-free for six months, on average have a less than $20 \%$ risk of recurrence in the next 12 months, our multivariable results indicated that the risk in some subgroups was significantly greater than $20 \%$. This included patients with a remote symptomatic seizure and an abnormal electroencephalogram result whether or not their computed tomography or magnetic resonance scan result was normal. For patients with a non-remote symptomatic seizure and abnormal electroencephalogram result and computed tomography or magnetic resonance imaging scan result the estimate was higher than $20 \%$ but the lower end of the confidence interval was less than $20 \%$.

Similarly, although the estimate from the unadjusted results suggested that patients who had not started antiepileptic drug treatment after a single seizure and who were seizure-free for six months had a less than $20 \%$ risk of recurrence in the next 12 months, our multivariable results indicated that some subgroups had a recurrence risk significantly greater than 20\%. This included patients with an abnormal electroencephalogram result and abnormal computed tomography or magnetic resonance scan result whether or not their seizure was remote symptomatic, and patients with a remote symptomatic seizure and an abnormal electroencephalogram result whether or not their computed tomography result was normal. For some subgroups the estimate was higher than $20 \%$ but the confidence interval included or was less than $20 \%$ : patients with a remote symptomatic seizure and an abnormal electroencephalogram result and computed tomography or magnetic resonance imaging scan result, and patients with a remote symptomatic seizure and a normal electroencephalogram result and abnormal computed 
Table $4 \mid$ Risk of seizure recurrence over 12 months at time points after index seizure: univariate model

\begin{tabular}{|c|c|c|c|}
\hline \multirow[b]{2}{*}{ Variables } & \multicolumn{3}{|c|}{ Risk of recurrence at time points $(95 \% \mathrm{Cl})$} \\
\hline & 6 months & 12 months & 18 months \\
\hline \multicolumn{4}{|l|}{ Cause of seizure: } \\
\hline Not remote symptomatic & 15 (12 to 19$)$ & 8 (5 to 11$)$ & 11 (7 to 14$)$ \\
\hline Remote symptomatic & 20 (10 to 30$)$ & 13 (4 to 22$)$ & $9(1$ to 17$)$ \\
\hline \multicolumn{4}{|l|}{ Neurological deficit: } \\
\hline Absent & 15 (12 to 18$)$ & 8 (6 to 11$)$ & 11 (7 to 14$)$ \\
\hline Present & 31 (13 to 49$)$ & $20(2$ to 37$)$ & - \\
\hline \multicolumn{4}{|l|}{ Seizures only while asleep: } \\
\hline Yes & 19 (11 to 28$)$ & $10(3$ to 17$)$ & 11 (3 to 19$)$ \\
\hline No & 15 (12 to 19$)$ & 9 (6 to 12$)$ & 10 (6 to 13$)$ \\
\hline \multicolumn{4}{|l|}{ EEG results: } \\
\hline Normal & 13 (9 to 17$)$ & 6 (3 to 9$)$ & 8 (4 to 12$)$ \\
\hline Abnormal & 19 (14 to 24$)$ & $12(8$ to 17$)$ & 13 (8 to 18$)$ \\
\hline Not done or missing* & 15 (1 to 29$)$ & $10(0$ to 23$)$ & - \\
\hline
\end{tabular}

tomography or magnetic resonance imaging scan result.

\section{DISCUSSION}

The UK Driving and Vehicle Licensing Agency have stated that after a single seizure drivers can regain their ordinary (group 1) licence once they have been free of seizures for six months provided no risk factors indicate a more than $20 \%$ risk of a recurrence over the next 12 months. ${ }^{5}$ The decision to reduce the time off driving from 12 to six months, in accordance with recent European Union recommendations, was in part informed by the data included in this paper. The challenge for clinicians and the Driving and Vehicle Licensing Agency is to identify the characteristics of patients who have a higher than $20 \%$ risk of seizure recurrence in the 12 months after a seizure-free period of six months. However, currently no published data can inform decisions as to whether an individual's risk is above or below this $20 \%$ threshold. We estimated these risks using data from the randomised controlled trial, MESS, assessing the policies of immediate and deferred drug treatment for epilepsy.

\section{Principal findings}

The results of our unadjusted analysis indicated that the risk of a seizure recurrence in the 12 months after a seizure-free period of six months was significantly below $20 \%$ for patients who started antiepileptic drug treatment (risk 14\%, 95\% confidence interval 10\% to $18 \%$ ). However, multivariable analyses identified subgroups whose risk was significantly higher than $20 \%$. For patients who did not start treatment the unadjusted estimate was below $20 \%$ but the upper limit of the confidence interval was greater than 20\% (risk 18\%, 13\% to 23\%). Multivariable analyses identified subgroups with a risk significantly more than $20 \%$. Driving regulators need to decide whether data from unadjusted analyses or subgroup analyses should be used to inform decisions. For example, regulators might use our unadjusted results to justify allowing anyone who starts antiepileptic drug treatment after a first seizure to drive once they have been seizure-free for six months, which would be in keeping with the new European Union standards. Alternatively, our multivariable analyses might be used to justify a decision to prevent subgroups with a higher risk of seizure recurrence from returning to driving, which is reflected in the current guidance from the Driving and Vehicle Licensing Agency.

\section{Strengths and weaknesses of the study}

One risk of using a randomised controlled trial such as MESS is the recruitment of a selected population that is not necessarily representative of the general population, which raises questions about generalisability of results. In MESS, the baseline characteristics of patients not randomised were similar to those randomised, which might argue against a major selection bias when patients made the decision to enter the trial or not. However, patients were given the opportunity to enter MESS only if the clinician was uncertain about the need to start treatment; thus patients entered into MESS might not be representative of the general population of patients presenting with a first seizure. This might have resulted in people at low risk of a seizure recurrence not entering the trial as they did not want to start treatment, and patients at a high risk of a seizure recurrence not entering the trial as they wanted to start treatment. Given the possibility that patients at both low or high risk of a recurrence did not enter MESS it is difficult to predict whether this would have caused an underestimation or overestimation of risks for seizure recurrence in the unadjusted analyses. In the multivariable analyses, this might have resulted in an overestimation of risk for subgroups at low risk of a recurrence and an underestimation of risk for patients at a high risk of a recurrence.

In MESS, most participants (75\%) were randomised within three months of their first seizure. Thus another potential selection bias is that some patients had a second seizure while waiting to see a specialist and were thus likely to start treatment at that point rather than join the trial. Thus MESS might have recruited patients with a lower risk of a seizure recurrence than the general population. It is unlikely that this has biased analyses, however, as patients with a recurrence within six months of their first seizure could not contribute to the risk estimates presented in this paper, as the estimates were conditional on being seizure-free for six or 12 months after a first seizure. In MESS, participants were seen predominantly by neurologists experienced at identifying and classifying seizures, but a further challenge in outpatient based studies of seizures and epilepsy, such as MESS, is that seizures are reported to the clinician by the patient and it is possible that patients under-report the occurrence of seizures. Validating patient reporting in an outpatient population with infrequent seizures is difficult and to date has not been done. If under-reporting of seizures has occurred, 
Table $5 \mid$ Risk of seizure recurrence in next 12 months estimated from multivariable model at specific seizure-free periods. Estimates presented assume seizures not confined to sleep and no first degree relative with epilepsy

\begin{tabular}{|c|c|c|c|c|c|c|c|}
\hline \multirow[b]{2}{*}{ Cause of seizure } & \multicolumn{2}{|c|}{ Test results } & \multirow[b]{2}{*}{$\begin{array}{l}\text { Months from } \\
\text { index seizure }\end{array}$} & \multicolumn{2}{|c|}{ Immediate treatment } & \multicolumn{2}{|c|}{ Delayed treatment } \\
\hline & EEG & $\mathrm{CT} / \mathrm{MRI}$ & & $\begin{array}{l}\text { Risk of seizure in next } \\
12 \text { months }(\%, 95 \% \mathrm{Cl})\end{array}$ & $\begin{array}{l}\text { Months from index seizure } \\
\text { until annual risk falls }<20 \%\end{array}$ & $\begin{array}{l}\text { Risk of seizure in next } \\
12 \text { months }(\%, 95 \% \mathrm{Cl})\end{array}$ & $\begin{array}{l}\text { Months from index seizure } \\
\text { until annual risk falls }<20 \%\end{array}$ \\
\hline \multirow[t]{2}{*}{ Not remote symptomatic } & Normal & Normal & 6 & $13(10 \text { to } 16)^{*}$ & 1.2 & $16(12 \text { to } 19)^{\star}$ & 3.2 \\
\hline & & & 12 & $7(5 \text { to } 10)^{\star}$ & & $9(6 \text { to } 12)^{\star}$ & \\
\hline \multirow[t]{2}{*}{ Not remote symptomatic } & Abnormal & Normal & 6 & 20 (16 to 23$)$ & 5.5 & 23 (20 to 26$)$ & 7.0 \\
\hline & & & 12 & $11(9 \text { to } 14)^{\star}$ & & $13(11 \text { to } 16)^{*}$ & \\
\hline \multirow[t]{2}{*}{ Not remote symptomatic } & Normal & Abnormal & 6 & $14(11 \text { to } 17)^{\star}$ & 2.1 & 17 (14 to 20$)$ & 3.6 \\
\hline & & & 12 & $8(5 \text { to } 11)^{\star}$ & & $10(7 \text { to } 12)^{\star}$ & \\
\hline \multirow[t]{2}{*}{ Not remote symptomatic } & Abnormal & Abnormal & 6 & 21 (18 to 24$)$ & 6.1 & $25(22$ to 28$) \dagger$ & 8.1 \\
\hline & & & 12 & $12(9 \text { to } 15)^{\star}$ & & $14(12 \text { to } 17)^{\star}$ & \\
\hline \multirow[t]{2}{*}{ Remote symptomatic } & Normal & Normal & 6 & 17 (14 to 20$)$ & 3.6 & 20 (17 to 23$)$ & 6.0 \\
\hline & & & 12 & $10(7 \text { to } 12)^{\star}$ & & $12(9 \text { to } 14)^{\star}$ & \\
\hline \multirow[t]{2}{*}{ Remote symptomatic } & Abnormal & Normal & 6 & 25 (22 to 28$) \dagger$ & 8.7 & $30(27$ to 32$) \dagger$ & 10.7 \\
\hline & & & 12 & $15(12 \text { to } 17)^{*}$ & & 18 (15 to 20$)$ & \\
\hline \multirow[t]{2}{*}{ Remote symptomatic } & Normal & Abnormal & 6 & 18 (15 to 21$)$ & 4.8 & 22 (19 to 25$)$ & 6.5 \\
\hline & & & 12 & $10(8 \text { to } 13)^{*}$ & & $13(10 \text { to } 15)^{\star}$ & \\
\hline \multirow[t]{2}{*}{ Remote symptomatic } & Abnormal & Abnormal & 6 & $27(24$ to 30$) \dagger$ & 9.2 & $32(29$ to 34$) \dagger$ & 11.3 \\
\hline & & & 12 & $16(13 \text { to } 18)^{*}$ & & 19 (16 to 21$)$ & \\
\hline
\end{tabular}

EEG=electroencephalogram; $C T=$ computed tomography; $M R I=$ magnetic resonance imaging

${ }^{*}$ Confidence interval lies completely below $20 \%$.

†Confidence interval lies completely above $20 \%$.

this would result in an underestimate of the risks of recurrence.

Although we cannot rule out the possibility and effects of biases from selection and reporting of seizures, MESS remains the largest reported study of early epilepsy and single seizures. The analysis presented in this paper allowed an estimation of risks of seizure recurrence after periods of being seizure-free and the identification of patients who might be at a high risk of recurrence.

\section{Comparison with other studies}

The National General Practice Study of Epilepsy ${ }^{15}$ is the only other study where risks of recurrence have been estimated after seizure-free periods. The trial was a population based study that recruited 564 patients with definite new onset seizures, which included 446 with unprovoked seizures, 83 with acute symptomatic seizures, and 35 with alcohol induced seizures. Overall, 252 patients had a single seizure as their index seizure, whereas the remainder were ascertained after their second or a subsequent seizure. While population based studies might be the ideal design to produce generalisable estimates of seizure recurrence risks, the results of the National General Practice Study of Epilepsy highlight potential problems with ascertainment in epilepsy studies, particularly where the outcome of importance is the risk of recurrence after a first seizure. In their paper assessing recurrence risks after a first seizure, the National General Practice Study of Epilepsy group reported analyses for time from first to second seizure for all patients and for the subgroup of patients where the index seizure was the first seizure. Risk estimates of recurrence were significantly lower for the group where the index seizure was the first seizure: $37 \%$ compared with $67 \%$ at 12 months. Survival curves were also given for the risk of a recurrence for the whole study population for a seizure-free period of six, 12, or 18 months after a first seizure. After six months of being seizure-free the risk of a recurrence over the next 12 months was about 35\% for the whole study population, substantially higher than the overall estimates in our analyses of MESS: 14\% with antiepileptic drug treatment and 18\% without treatment. For the population in the National General Practice Study of Epilepsy where the first seizure was the index seizure (comparable population in our analyses), the risk of a recurrence over the next 12 months after a seizure-free period of six months was about 18\%, similar to the estimate in our analysis of MESS. This highlights the importance of ascertaining patients after their first seizure rather than after a second or subsequent seizure. Multivariable analyses of the National General Practice Study of Epilepsy identified symptomatic seizures, neurological deficit, and no antiepileptic drug treatment as risk factors for a recurrence of seizure after a first seizure, which were also identified in MESS. Data from the National General Practice Study of Epilepsy have not been used to estimate the risks of recurrence in the next 12 months for patients seizure-free for various periods for individual risk groups, and with a fairly small sample size validation may not be reliable.

\section{Meaning of the study}

The unadjusted estimates suggest that after a first seizure, the overall risk of a recurrence in the 12 months after a seizure-free period of six months is below $20 \%$. The confidence intervals around estimates suggest that this risk is significantly below $20 \%$ for patients who 


\section{WHAT IS ALREADY KNOWN ON THIS TOPIC}

People who start treatment after a first seizure have a lower risk of recurrence than those who do not

Prognostic models have shown that people with an abnormal electroencephalogram result or neurological deficit have a higher risk of a seizure recurrence

\section{WHAT THIS STUDY ADDS}

Six months after an index seizure the overall risk of recurrence in the following 12 months was significantly below $20 \%$ for people who started antiepileptic drug treatment

Seizure while asleep and abnormal electroencephalogram results significantly increase the risk of a seizure recurrence in the next 12 months according to a multivariable analysis

start antiepileptic drug treatment, but not for those who do not. The univariate and multivariable analyses allow the identification of patients who are at differing risks of recurrence and hence those who might be at high or low risk of recurrence at specific time points after a first seizure. However, guidance is needed from driving regulators as to how far to individualise risk and whether clinicians should focus on unadjusted results when making recommendations about driving, or on results from univariate or multivariable models. It could be argued that at the population level the risk (ignoring the confidence interval) of a seizure recurrence is below $20 \%$ after a six month seizure-free period; thus all patients should be able to regain their driving licence, accepting that some in the population will have a risk above $20 \%$. Alternatively, a more conservative approach could be taken to individualise risk. The multivariable model identifies several subgroups that have a risk of recurrence that is significantly greater than $20 \%$ after a six month seizure-free period. This includes those with a non-remote symptomatic seizure who do not start treatment and have both an abnormal electroencephalogram results and an abnormal computed tomography or magnetic resonance imaging scan result and those with a remote symptomatic seizure and an abnormal electroencephalogram result, irrespective of the result for computed tomography or magnetic resonance imaging or treatment policy. Additionally, the risk estimate for several subgroups was greater than 20\%, although the lower confidence limit was below 20\%. Similarly, the estimate for some subgroups was below $20 \%$ but the upper limit of the confidence interval was above $20 \%$. Any attempt to utilise these data to inform driving policy could have important implications on resources for health services, as investigations such as electroencephalography may be required that are not otherwise clinically indicated, and patients could choose to take antiepileptic drug treatment, which is not otherwise clinically indicated.

\section{Unanswered questions and future research}

Further research and guidance are required to inform risk based policies, including regulations about returning to driving after a single seizure. To inform recommendations about driving, clinicians and patients require guidance as to whether the focus should be on risk estimates alone or on risks and their associated confidence intervals. If the focus is on the estimate only, our unadjusted estimates suggest that treated and untreated patients are eligible to drive after being seizure-free for six months. If the focus is on the risk estimate and its associated confidence interval, a patient who starts treatment will be eligible to drive after being seizure-free for six months. For patients who do not start treatment the advice depends on the perspective taken. A conservative approach would allow patients to regain their licence once the upper confidence interval has dropped below 20\%. This would prevent patients who do not start treatment from returning to driving after being seizure-free for six months, and potentially coerce people into taking antiepileptic drug treatment that is not otherwise clinically indicated. A more liberal approach would be to allow people to regain their licence provided that the lower confidence limit is below 20\%. This approach could result in those at a high risk of recurrence regaining their licence. An intermediate approach might be to require the risk estimate to be below $20 \%$ and also to define the upper limit of the confidence interval that would be acceptable.

This reanalysis of MESS provides data that can potentially inform decisions about returning to driving for people who have had a first unprovoked seizure. MESS recruited a broad heterogeneous population, which has allowed the investigation of factors that influence seizure recurrence presented in this paper. Results should therefore be relevant to the general population, but selection bias may be at play and some caution is required in interpreting results. Ideally, external validation of the models presented here is required and we are in the process of establishing a consortium to attempt to validate and refine our models. The MESS data allow an estimation of seizure recurrence risk conditional on having been seizurefree for six or 12 months. Further guidance is now required from driving authorities as to how these data should be interpreted. In particular, guidance is needed as to whether a population approach should be taken, with a focus on unadjusted results or whether attempts should be made to individualise risk. Guidance is also required as to whether the focus should be on risk estimates only or on the confidence interval as well. If the confidence interval is to be included, guidance is needed as to whether the conservative, liberal, or intermediate approach should be taken.

We thank $\mathrm{C}$ Warlow and $\mathrm{M}$ Walker for their comments on the manuscript. Contributors: LJB analysed the data and drafted and revised the paper.

CT-S and PRW provided support for statistical analyses and drafted and revised the paper. AGM joint coordinated the MESS trial, provided clinical input, and drafted and revised the paper. AGM is guarantor. Funding: This study (RP-PG-0606-1062) was supported by the National Institute for Health Research programme grants for applied research funding scheme. The original trial was funded by the Medical Research Council. The views and opinions expressed within this paper do not necessarily reflect those of the National Health Service, the National Institute for Health Research, or the Department of Health. The researchers are independent from the funders. 
Competing interests: All authors have completed the Unified Competing Interest form at www.icmje.org/coi_disclosure.pdf (available on request from the corresponding author) and declare: no support from any company for the submitted work; no financial relationships with any companies that might have an interest in the submitted work in the previous 3 years; no other relationships or activities that could appear to have influenced the submitted work. PRW and AGM sit on the Secretary of State for Transport's Honorary Advisory Panel on Driving and Disorders of the Nervous System.

Ethical approval: Not required as this was a reanalysis of data. Data sharing: Statistical code and dataset are available from the corresponding author at A.G.Marson@liverpool.ac.uk.

1 Fisher RS, Parsonage M, Beaussart M, Bladin P, Masland R, Sonnen $\mathrm{AEH}$, et al. Epilepsy and driving —an international perspective. Epilepsia 1994;35:675-84.

2 Second European Working Group on Epilepsy and Driving. Epilepsy and driving in Europe. 2005. http://ec.europa.eu/transport/ road_safety/behavior/doc/ epilepsy_and_driving_in_europe_final_report_v2_en.pdf.

3 European Commission for Transport. 2010. http://ec.europa.eu/ transport/index_en.htm.

4 Schmedding E. Epilepsy and driving in Belgium: proposals and justification. Acta Neurologica Belgica 2004;104:68-79.

5 Driver and Vehicle Licensing Agency. At a glance guide to the current medical standards of fitness to drive. Drivers Medical Group, 2010. www.dft.gov.uk/dvla/medical/ataglance.aspx.
6 Krauss GL, Ampaw L, Krumholz A. Individual state driving restrictions for people with epilepsy in the US. Neurology 2001;57:1780-5.

7 Kim LG, Johnson TL, Marson AG, Chadwick DW. Prediction of risk of seizure recurrence after a single seizure and early epilepsy: further results from the MESS trial. Lancet Neurol 2006;5:317-22.

8 Prognosis of epilepsy in newly referred patients: a multicenter prospective study of the effects of monotherapy on the long-term course of epilepsy. Collaborative Group for the Study of Epilepsy. Epilepsia 1992;33:45-51.

9 Marson A, Jacoby A, Johnson A, Kim L, Gamble C, Chadwick D. Immediate versus deferred antiepileptic drug treatment for early epilepsy and single seizures: a randomised controlled trial. Lancet 2005;365:2007-13.

10 Cox DR, Oakes D. Analysis of survival data. Chapman and Hall, 1984.

11 Davis FG, McCarthy BJ, Freels S, Kupelian V, Bondy ML. The conditional probability of survival of patients with primary malignant brain tumors-surveillance, epidemiology, and end results (SEER) data. Cancer 1999;85:485-91.

12 Lin CL, Lieu AS, Lee KS, Yang YH C, Kuo TH, Hung MH, et al. The conditional probabilities of survival in patients with anaplastic astrocytoma or glioblastoma multiforme. Surg Neurol 2003;60:402-6.

13 Akaike $\mathrm{H}$. A new look at the statistical model identification. IEEE Trans Automat Contr 1974:19:716-23.

14 Collett D. Modelling survival data in medical research. Chapman and Hall, 2003.

15 Hart YM, Sander JW, Johnson AL, Shorvon SD. National General Practice Study of Epilepsy: recurrence after a first seizure. Lancet 1990;336:1271-4.

Accepted: 22 September 2010 